\title{
Semiconducting Behavior of Carbon Steel in Electrolyte Solution
}

\author{
Q.D. Zhong ${ }^{*}, 1,2$, C. Wang $^{1}$, X.G. Lu ${ }^{1}$, L.Y. Shi ${ }^{2}$ and K.C. Chou ${ }^{1}$ \\ ${ }^{1}$ Key Lab of Modern Metallurgy \& Materials Processing, School of Materials Science and Engineering, Shanghai Uni- \\ versity, Shanghai, 200072, China \\ ${ }^{2}$ Nano Science and Technology Research Center, Shanghai University, Shanghai, 200444, China
}

\begin{abstract}
In this paper, the semiconducting behavior of carbon steel in acid, base and salt solutions was studied by utilizing potential-capacitance and Mott-Schottky analysis. It was pointed out that the capacitance variation of space charge layer of carbon steel in different solution was different. The carbon steel showed p-type semiconducting behavior in $5 \%$ sulfuric acid and 5\% sodium sulfate solution. However, the carbon steel showed n-type semiconducting behavior in 5\% sodium hydroxide. It was suggested that the space charge layer of the carbon steel in different electrolytes might be asymmetric.
\end{abstract}

Keywords: Carbon steel, conducting mechanism, p-type semiconductor, n-type semiconductor.

\section{INTRODUCTION}

It is well known that stainless steels and the film have drawn much concern for almost 170 years [1]. It still represents a special and favorite topic for electrochemists and material scientists on this topic [2-21]. In general, passive film on the surface of stainless steel could be interpreted in terms of a semiconductive film. Capacitance measurements and photoelectrochemistry are often utilized to study the conducting behavior of passive films and to obtain the donor density $\left(\mathrm{N}_{\mathrm{D}}\right)$ and the flat band potential $\left(\mathrm{E}_{\mathrm{fb}}\right)$ by analysis of Mott-Schottky plots [11, 22-26]. The results suggested the passive film over the stainless steel which exhibits an n-type semiconductor with high density of $10^{25} \sim 10^{27} \mathrm{~m}^{-3}$. The capacitance measurements at different frequencies indicated that the passive film was amorphous or a strongly disordered semiconductor. Simoes et al. observed that Mott-Schottky plots of passive films formed on 304 stainless steel were nonlinear [22].

Theoretical studies of mechanism of this kind of semiconducting film have been well investigated in the classic theory of solid state physics. Electron transport through such film can be affected by two mechanisms: If the film is highly doped with electron donors or acceptors, the electrons are transported via the conduction or the valence band. In heavily disordered films, which have a high concentration of localized electronic states in the band gap, electron transfer through the film can occur by a series of hops between such states; this is a so-called hopping conductivity mechanism. Many models have been used to study and describe these disordered systems such as ion implantation [27,28], passive film [29,32], and polymer films with localized electronic states [30] etc. Hopping conductivity in disordered systems is also well documented [31]. In addition, Clayton et al.

*Address correspondence to this author at the Key Lab of Modern Metallurgy \& Materials Processing, School of Materials Science and Engineering, Shanghai University, No.149 Yanchang Road, Mail Box No.275, Shanghai, 200072, China; Tel: +86/(0)21-56338244; Fax: +86/(0)21-56338244;

E-mail: qdzhong@hotmail.com observed the evidence for a bipolar mechanism of passivity in Mo bearing stainless steels [33].

A large amount of research has been performed on stainless steel [11, 22-26] and metals including beryllium [34], aluminum [35], titanium [36], zinc [37], gallium [38], copper [39], nickel [40], tungsten [41] etc. to study the electronic structure and semiconductive properties of passive film. In our previous study of temporarily protective oil coating (TPOC) on its electrochemical inhomogeneity [41-45], voltammetric investigation suggested the potential variation of oil coating during its degradation. At the early stage of immersion, anodic reaction was a rate-determining step in the overall reaction in metal/oil/electrolyte system, which has a potential to shift positively with varying immersion time. After being immersed for some time, the potential of oil coating shifted towards corrode direction with increasing immersion time; at this stage ionic diffusion in the coating was predominant [42].

Previous studies of capacitance measurement with MottSchottky analysis showed that on the surface of AISI 304 stainless steel, the temporarily protective oil coating behaved as a semiconductor during its degradation. With the increasing immersion time, temporarily protective oil coating transformed from p-type semiconductor at the early stage of immersion to n-type semiconductor [46].

Though there are some studies on the electric and electronic structure of carbon steel [47-49], little work has been done in semiconducting behavior of carbon steel in different electrolyte. In this paper, we utilized capacitance measurement with Mott-Schottky analysis to study the conducting behavior of carbon steel in 5\% sulfuric acid, 5\% sodium sulfate and $5 \%$ sodium hydroxide solutions varying with immersion time.

\section{EXPERIMENTAL}

The electrode samples prepared in this paper were made of a carbon steel rod containing $0.20 \mathrm{wt} \% \mathrm{C}$, named as No.20 carbon steel by Chinese Standard having a diameter of 
$10 \mathrm{~mm}$. The working electrode was embedded in an epoxy resin, resulting in an exposed steel area of $0.785 \mathrm{~cm}^{2}$. The working surface of the electrode was polished with emery paper to 800 grit, degreased with acetone, and then the electrode was separately immersed in a $5 \%(\mathrm{w} / \mathrm{w})$ sulfuric acid, $5 \%(\mathrm{w} / \mathrm{w})$ sodium sulfate and $5 \%(\mathrm{w} / \mathrm{w})$ sodium hydroxide solution for capacitance measurement. The solutions were made from analytical grade reagent and distilled water. All tests were carried out at ambient temperature.

All testing electrode samples were introduced in a conventional three-electrode electrochemical cell. The capacitance of electrode sample was measured at $1000 \mathrm{~Hz}$ in the potential range $-0.5 \mathrm{~V}$ to $0.5 \mathrm{~V}$ by performing a potential scan in the positive direction with a computer-controlled Electrochemistry Station Model CHI660C. The reference electrode was a saturated calomel electrode (SCE), and a platinum wire was used here as the counter electrode.

The Mott-Schottky relationship of $\left(1 / \mathrm{C}_{\mathrm{sc}}\right)^{2}$ vs $\mathrm{U}$ expressed the potential dependence of $\mathrm{C}_{\mathrm{SC}}$ of a semiconductor electrode under the depletion condition, for n-type semiconductor,

$\frac{1}{C_{s c}^{2}}=\frac{2}{\varepsilon \varepsilon_{0} e N_{D}}\left(U-U_{f b}-\frac{k T}{e}\right)$

For p-type semiconductor,

$\frac{1}{C_{s c}^{2}}=-\frac{2}{\varepsilon \varepsilon_{0} e N_{A}}\left(U-U_{f b}-\frac{k T}{e}\right)$

where Csc is space charge capacitance, $\varepsilon$ is the dielectric constant of the charge layer for carbon/electrolyte, $\varepsilon_{0}$ is permittivity of free space $\left(8.854^{*} 10^{-12} \mathrm{~F} / \mathrm{m}\right)$, e is the charge of electron, $\mathrm{N}_{\mathrm{D}}$ and $\mathrm{N}_{\mathrm{A}}$ are density of donor and acceptor respectively, $\mathrm{U}_{f b}$ is flat band potential, $k$ is Boltzmann constant, $\mathrm{T}$ is absolute temperature.

A set of impedance values of all electrode samples varied with potential and immersion time were also obtained from capacitance measurements.

\section{RESULTS AND DISCUSSION}

\subsection{Capacitance Variation of No.20 Carbon Steel During its Degradation in Different Electrolyte}

The capacitance-potential curves of electrodes showed capacitance variation with immersion in different electrolyte solution (Figs. 1,3). For No.20 carbon steel in 5\% sulfuric acid solution (Fig. 1), with increasing potential, the capacitance increased. The variation of capacitance may be due to a decreasing thickness of the depletion layer and increasing number of charge carriers (donor for an n-type semiconductor) [47]. For No.20 carbon steel in 5\% sodium sulfate solution (Fig. 2), the capacitance increased. This phenomenon for variation of capacitance could be interpreted as a decreasing thickness of the depletion layer and increasing number of charge carriers. For the two kinds of electrolytes, with increasing immersion time, the capacitances had the inclination of increasing gradually, these may be due to ionic diffusion and penetration in the space charge layer on the surface of the carbon steel in the electrolytes, and due to increasing number of charge carriers.

However, for the electrolyte of $5 \%$ sodium hydroxide solution, the results were different. For No.20 carbon steel in
$5 \%$ sodium hydroxide solution (Fig. 3), there were two valleys in the capacitance-potential plot. The peaks of valleys were at the potential of $-0.3 \mathrm{~V} v s$ SCE and $0.4 \mathrm{~V} v s$ SCE respectively. With increasing potential, the capacitance had a decreasing trend. The variation of capacitance may be due to increasing thickness of the depletion layer and decreasing number of charge carriers. With increasing immersion time, the capacitances had an inclination of increasing gradually, these may be due to ionic diffusion and penetration in the space charge layer on the surface of the carbon steel in the electrolyte, and then increasing number of charge carriers. When the potential was higher than $0.4 \mathrm{~V}$ vs SCE, the capacitance began to increase sharply.

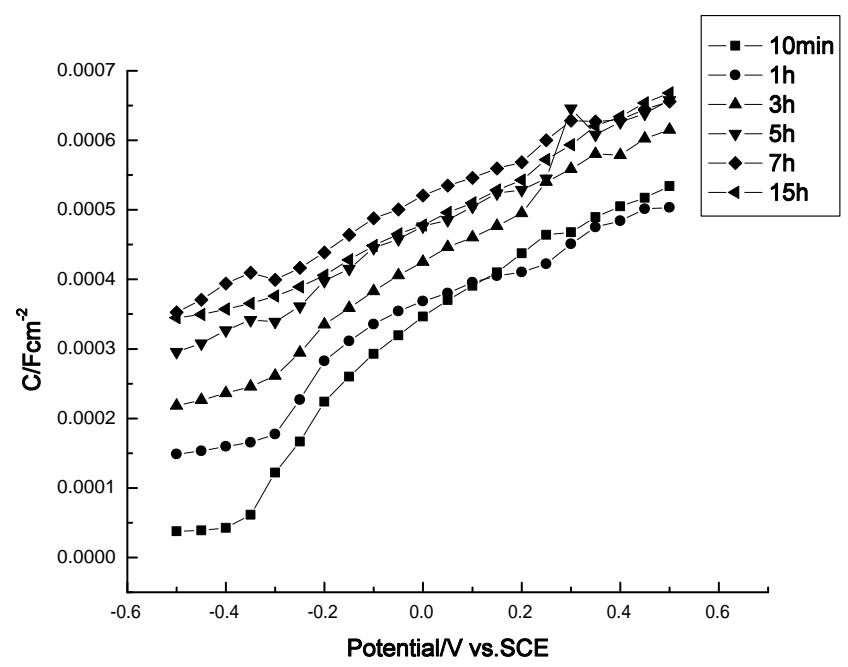

Fig. (1). The capacitance-potential curve of No.20 carbon steel obtained at $1000 \mathrm{~Hz}$ with different immersing time in $5 \%$ sulfuric acid solution.

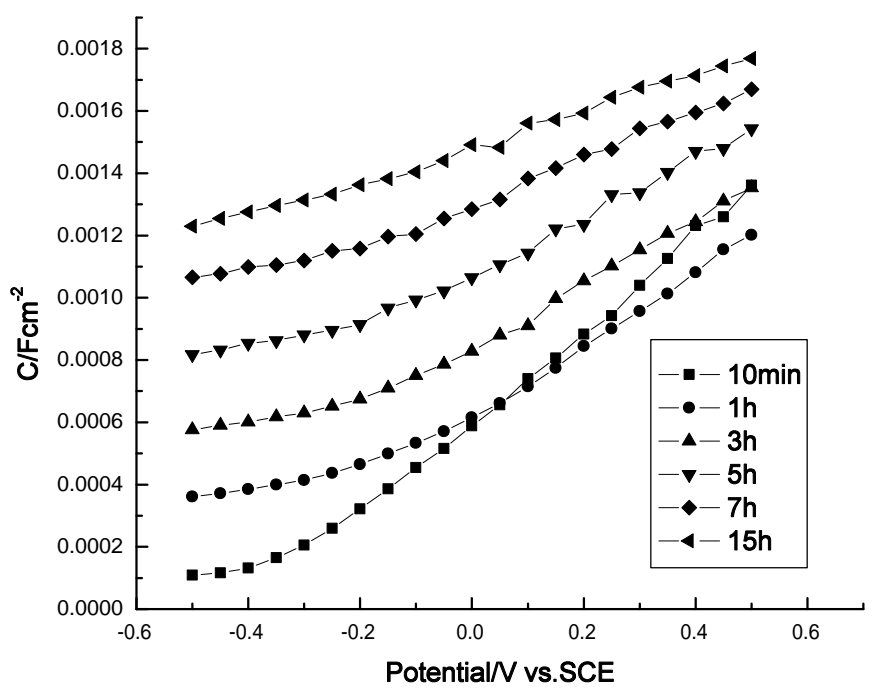

Fig. (2). The capacitance-potential curve of No.20 carbon steel obtained at $1000 \mathrm{~Hz}$ with different immersing time in 5\% sodium sulfate solution.

3.2. Analysis of Mott-Schottky Plot for Carbon Steel During its Degradation in Different Electrolyte

The charge distribution at the semiconductor and electrolyte interface was often determined by measuring the capaci- 
tance of the space-charge layer $\left(\mathrm{C}_{\mathrm{SC}}\right)$ as a function of the electrode potential (U).

We calculated the values of $\left(1 / \mathrm{C}_{\mathrm{sc}}\right)^{2}$ of the carbon electrode and plotted with the potential shown in Figs. $(4,6)$.

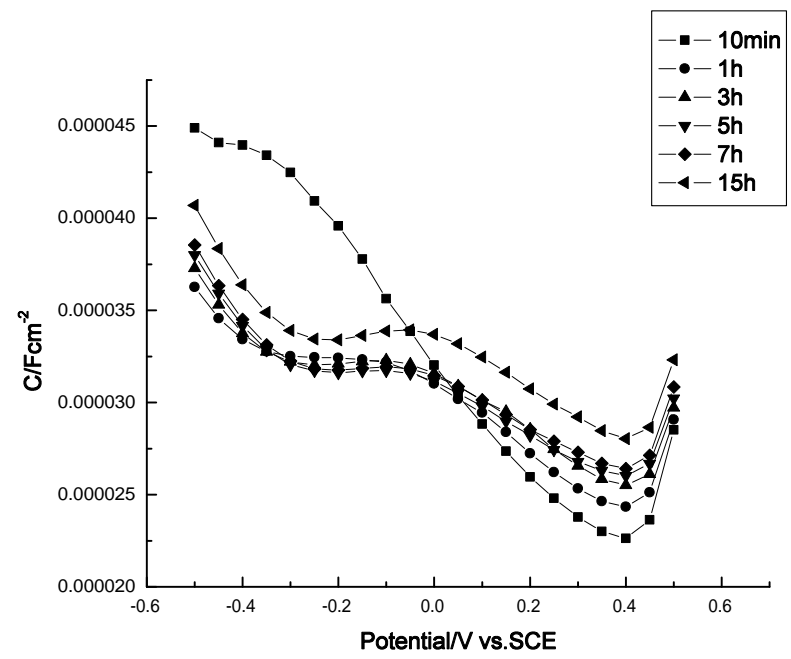

Fig. (3). The capacitance-potential curve of No.20 carbon steel obtained at $1000 \mathrm{~Hz}$ with different immersing time in $5 \%$ sodium hydroxide solution.

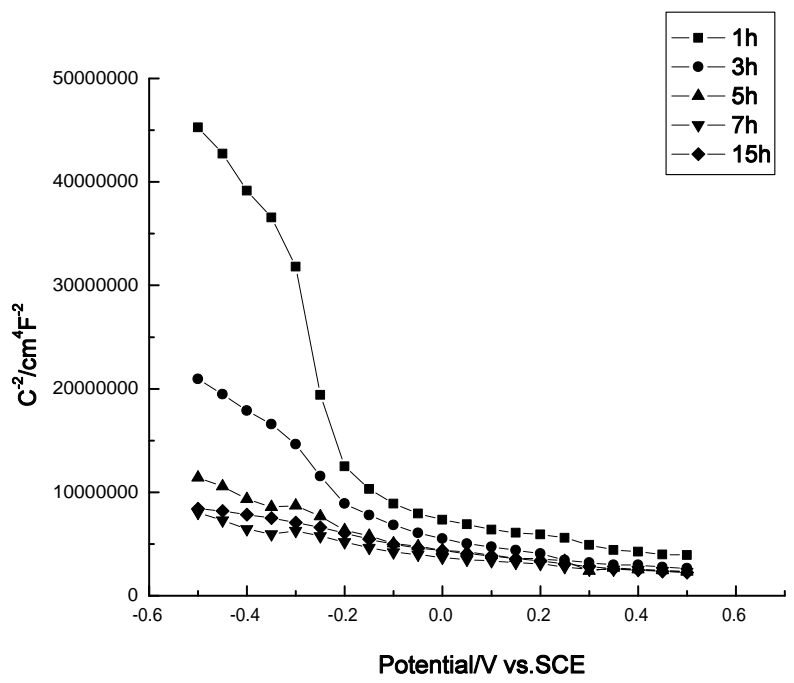

Fig. (4). The Mott-Schottky plot of No.20 carbon steel obtained at $1000 \mathrm{~Hz}$ with different immersing time in 5\% sulfuric acid solution.

For No.20 carbon steel in 5\% sulfuric acid solution (Fig. 4), the Mott-Schottky curve was nonlinear with immersions of 1 hour and 3 hours. This was the same as that of paper [22]. With increasing immersion time, Fig. (4) depicted a linear correlation between values of $\left(1 / \mathrm{C}_{\mathrm{sc}}\right)^{2}$ and the potential of the electrode in $5 \%$ sulfuric acid solution at the potential range of $-0.5 \mathrm{~V} \sim 0.5 \mathrm{~V}$. The depletion layer behaved as a $\mathrm{p}-$ type semiconductor (negative slope), and the slope of the Mott-Schottky plot decreased gradually. This suggested that with increasing immersion time, acceptor of density $\left(\mathrm{N}_{\mathrm{A}}\right)$ increased gradually.

For No.20 carbon steel in 5\% sodium sulfate solution (Fig. 5), the Mott-Schottky curve was linear with immersion time. Fig. (5) depicted a linear correlation between values of $\left(1 / \mathrm{C}_{\mathrm{sc}}\right)^{2}$ and the potential of the electrode in $5 \%$ sodium sulfate solution at the potential range of $-0.5 \mathrm{~V} \sim 0.5 \mathrm{~V}$. The de- pletion layer also behaved as a p-type semiconductor (negative slope), and the slope of the Mott-Schottky plot decreased gradually. This suggested that with increasing immersion time, acceptor of density $\left(\mathrm{N}_{\mathrm{A}}\right)$ increased gradually. This situation was different with the passive film of carbon steel prepared in the atmosphere, which showed n-type semiconductor [47-49].

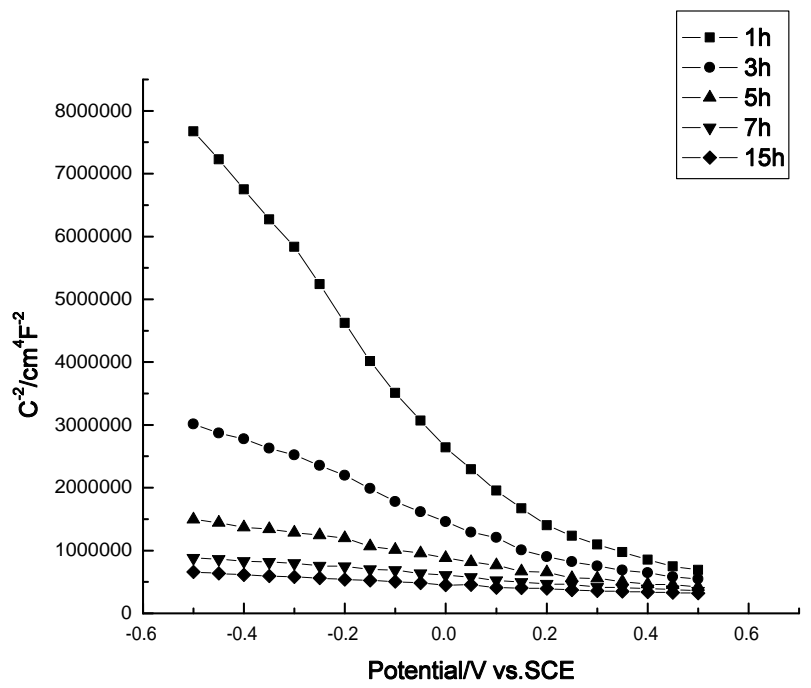

Fig. (5). The Mott-Schottky plot of No.20 carbon steel obtained at $1000 \mathrm{~Hz}$ with different immersing time in $5 \%$ sodium sulfate solution.

Fig. (6) showed the results of the capacitance measurements of the No.20 carbon steel in 5\% sodium hydroxide solution, plotted as $\mathrm{C}^{-2} v s$ potential (U). Two linear regions revealing Mott-Schottky behavior could be attributed to the development of depletion layers promoted by band bending. For No.20 carbon steel in 5\% sodium hydroxide solution (Fig. 6), there were two peaks in the Mott-Schottky plot. The peaks were also at the potential of $-0.3 \mathrm{~V} v s \mathrm{SCE}$ and $0.4 \mathrm{~V} v s$ SCE, respectively compared with the Fig. (3). At the potential range of $-0.5 \mathrm{~V} \sim-0.3 \mathrm{~V} v s \mathrm{SCE}$ and $0 \mathrm{~V} \sim 0.4 \mathrm{~V} v s \mathrm{SCE}$, Fig. (6) depicted a linear correlation between values of $\left(1 / \mathrm{C}_{\mathrm{sc}}\right)^{2}$ and the potential of the electrode in $5 \%$ sodium hydroxide solution. The depletion layer of the carbon steel, however, behaved as an n-type semiconductor (positive slope), and the slope of the Mott-Schottky plot had the inclination of decreasing gradually. This suggested that with increasing immersion time, donor of density $\left(\mathrm{N}_{\mathrm{D}}\right)$ increased gradually. Compared with the values of $\left(1 / \mathrm{C}_{\mathrm{sc}}\right)^{2}$ shown in Figs. $(4,6)$, it was obvious that $\mathrm{N}_{D}$ of the carbon steel in $5 \%$ sodium hydroxide was three orders of magnitude higher than that of $\mathrm{N}_{\mathrm{A}}$ in $5 \%$ sulfuric acid and $5 \%$ sodium sulfate, respectively. Considering the ions (including cation or anion) in the electrolyte could not change the $\varepsilon$ (the dielectric constant of the charge layer for carbon/electrolyte) so sharply, thus this situation might be due to asymmetry of carbon/electrolyte system for different solution.

In our previous study of metal/oil coating/electrolyte system [50], it was pointed out that at the early stage of immersion of oil-coated metal specimen, the electrochemical reactions in metal/coating/electrolyte system were very small, the amount of metal cation produced at the metal/coating interface was ultra small, and the amount of corresponding anion creating at the coating/electrolyte was very small. These ions 
could not diffuse through the coating and constructed steady diffusion passway in the oil coating. At this time, only electron could transfer through the coatings by electrons hopping the localized electronic states in organic coatings. Electrochemical reaction in the metal/coating/electrolyte system was determined by any one-step, which directly related to metal cation formation and transmission in the metal/coating/electrolyte system. At this time, oil coating behave as a p-type semiconductor. However, the density of $\mathrm{N}_{\mathrm{A}}$ was very small.

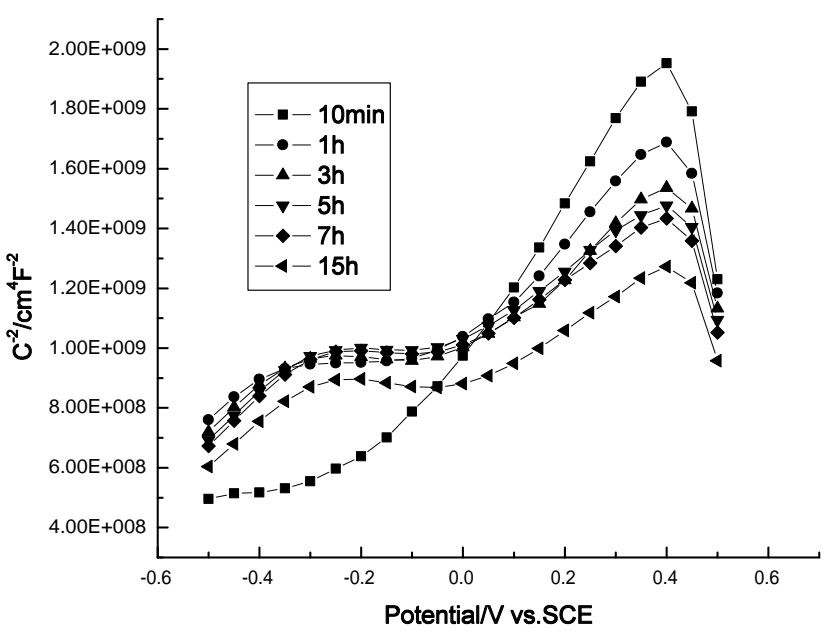

Fig. (6). The Mott-Schottky plot of No.20 carbon steel obtained at $1000 \mathrm{~Hz}$ with different immersing time in $5 \%$ sodium hydroxide solution.

With the increase of immersion, ions in the electrolyte began to diffuse in the oil coating, and gradually constructed the steady diffusion layer in the coating. At this time, electrochemical reaction in the metal/coating/electrolyte system was determined by any one step concerning with electron transmitting in the overall reaction of metal/coating/electrolyte system. Considering the steps of cation producing and transmitting in the oil coating was in equilibrium, in order to keep the charge equilibrium in the oil coating and prevent charge accumulation in the metal/coating /electrolyte system, the amount of cations producing at the metal/coating interface and transmitting through the coating were equal to the amount of anion producing of the cathodic reaction (oxygen reduction, $\mathrm{O}_{2}+2 \mathrm{H}_{2} \mathrm{O}+4 \mathrm{e}^{-} \rightarrow 4 \mathrm{OH}^{-}$) at coating/electrolyte interface.

From above analysis, it was clear that cathodic processes concerning with the electron production, electron transmitting in the coating and electron consuming at coating/electrolyte interface were predominant, whereas anodic processes in the metal/coating/electrolyte were in equilibrium. At this time, oil coating behaved as an n-type semiconductor, and the density of $\mathrm{N}_{\mathrm{D}}$ was much higher than that of $\mathrm{N}_{\mathrm{A}}$, which the oil coating being at the early stage of immersion.

For the mechanism analysis of metal/oil coating system in the same salt solution, in metal/oil coating/electrolyte system, $\mathrm{N}_{\mathrm{D}}$ was much higher than that of $\mathrm{N}_{\mathrm{A}}$, the space charge layer in the system was asymmetric with time. However, for the carbon steel in different electrolyte at the same time, $\mathrm{N}_{\mathrm{D}}$ of the carbon steel/electrolyte fast electrochemical system was much higher than that of $\mathrm{N}_{\mathrm{A}}$, this was the same as that of metal/oil coating/electrolyte system. It was suggested that the space charge layer in the carbon/electrolyte system might be asymmetric for different solution.

\section{CONCLUSION}

The results of our investigations had led to the following conclusions:

1) The capacitance variation of space charge layer of No.20 carbon steel in different solution was different;

2) The carbon steel showed p-type semiconducting behavior in 5\% sulfuric acid and 5\% sodium sulfate solution;

3) The carbon steel showed n-type semiconducting behavior in 5\% sodium hydroxide. 4) The space charge layer of the carbon steel in different electrolyte might be asymmetric.

\section{ACKNOWLEDGEMENT}

This paper is financially supported by Natural Science Foundation of China 50571059, 50615024, and Program for New Century Excellent Talents in University NCET-070536, Innovative Research Team in University IRT0739, the Science Foundation of Shanghai Municipal Commission of Science and Technology (Contract No. 06dz05902, 0652nm 038, 07xd14014).

\section{REFERENCES}

[1] Uhlig H. Passivity of Metals, The Electrochemistry Society. In: Frankenthal RP, Kruger J, Eds. The Corrosion Monograph Series Princeton NJ 1978; vol. 1.

[2] Zhang L, Macdonald DD. Segregation of alloying elements in passive systems-I. XPS on the Ni-W system. Electrochim Acta 1998; 43(18): 2661-71.

[3] Cheng YF, Luo JL. Electronic structure and pitting susceptibility of passive film on carbon steel. Electrochim Acta 1999; 44(17): 2947 57.

[4] Sikora J, Sikora E, Macdonald DD. The electronic structure of the passive on tungsten. Electrochim Acta 2000; 45(12): 1875-83.

[5] Cho EA, Kim CK, Kim JS, Kwon HS. Quantitative analysis of repassivation kinetics of ferritic stainless steels based on the high field ion conduction model. Electrochim Acta 2000; 45(12): 193342.

[6] Bojinov M, Fabricius G, Laitinen T, et al. Coupling between ionic defect structure and electronic conduction passive films on iron, chromium and iron -chromium alloys. Electrochim Acta 2000; 45(13): 2029-48

[7] Schultze JW, Lohrengel MM. Stability, reactivity and breakdown of passive film: problems of recent and future research. Electrochim Acta 2000; 45(13): 2499-513.

[8] Hakiki NE, Boudin S, Rondot B, Belo MDC. The electronic structure of passive films formed on stainless steels. Corros Sci 1995; 37(11): 1809-22.

[9] Li W, Luo J. Electric properties and pitting susceptibility of passive films formed on iron in chromate solution. Electrochem Commun 1999; 1(8): 349-53.

[10] Vilche JR, Juttner K, Lorenz WJ, et al. Semiconductor properties of passive films on $\mathrm{Zn}, \mathrm{Zn}-\mathrm{Co}$, and $\mathrm{Zn}-\mathrm{Ni}$ substrates. J Electrochem Soc 1989; 136(12): 3773-9.

[11] Schmuki P, Bohni H. Metastable pitting and semiconductive properties of passive films. J Electrochem Soc 1992; 139(7): 1908-13.

[12] Moffat TP, Yang H, Fan FRF, Bard AJ. Electron-transfer reactions on passive chromium. J Electrochem Soc 1992; 139(11): 3158-67.

[13] Kek D, Gaberscek M, Pejovnik S. All-solid-state measurements of electrical properties of passive films on lithium. J Electrochem Soc 1996; 143(5): 1690-5. 
[14] Hakiki NE, Da Cunha Belo M. Electronic structure of passive films formed on molybdenum-containing ferritic stainless steels. J Electrochem Soc 1996; 143(10): 3088-94.

[15] Macdonald DD, Ismail KM, Sikora E. Characterization of the passive state on Zinc. J Electrochem Soc 1998; 145(9): 3141-49.

[16] Hakiki NE, Da Cunha Belo M, Simoes AMP, Ferreira MGS. Semiconducting properties of passive films on stainless steels. J Electrochem Soc 1998; 145(11): 3821-9.

[17] Santamaria M, Huerta D, Piazza S, Sunseri C, Di Quarto F. The influence of the electronic properties of passive films on the corrosion resistance of Mo-Ta alloys. A photoelectrochemical study. J Electrochem Soc 2000; 147(4): 1366-75.

[18] Yang MZ, Luo JL, Yang Q, et al. Effects of hydrogen on semiconductivity of passive films and corrosion behavior of 310 stainless steel. J Electrochem Soc 1999; 146(6): 2107-12.

[19] Davenport AJ, Oblonsky LJ, Ryan MP, Toney MF. The structure of the passive film that forums on iron in aqueous environments. $J$ Electrochem Soc 2000; 147(6): 2162-73.

[20] Yang MZ, Luo JL, Patchet BM. Correlation of hydrogen-facilitated pitting of AISI 304 stainless steel to semiconductivity of passive films. Thin Solid Films 1999; 354(1-2): 142-7.

[21] Tringe J, Deal MD, Plummer JD. Transparent probe test structure for electrical and physical characterization of defects in thin films. J Electrochem Soc 2000; 147(12): 4633-8.

[22] Simoes AMP, Ferreira MGS, Rondot B, da Cunha Belo M. Study of passive films formed on AISI 304 stainless steel by impedance measurements and photoelectrochemistry. J Electrochem Soc 1990; 137(1): 82-7.

[23] Paola AD, Shukla D, Stimming U. Photoelectrochemical study of passive on stainless steel in neutral solutions. Electrochim Acta 1991; 36(2): 345-52.

[24] Paola AD. Semiconducting properties of passive films on stainless steels. Electrochim Acta 1989; 34(2): 203-10.

[25] Burleigh TD, Latanision RM. The use of photocurrents to characterize anodic films on $\mathrm{Ti}, \mathrm{Zr}, \mathrm{Cu}$, and 304 stainless steel. J Electrochem Soc 1987; 134(1): 135-41.

[26] Harrison JA, Williams DE. How does the electrochemical behavior of stainless steel reflect that of its constituent elements. Electrochim Acta 1986; 31(8): 1063-72.

[27] Bartels C, Danzfuss B, Schultze JW. Passivity of metals and semiconductors. Froment M, Ed. Elsevier, Amsterdam 1983.

[28] Schultze JW, Elfenthal L, Leitner K, Meyer O. Electrochemical studies of titanium dioxide films with various palladium implantation profiles. Mat Sci Eng 1987; 90: 253-62.

[29] Leiva E, Meyer P, Schmickler W. A simulation of percolation process in electrochemical systems. J Electrochem Soc 1988; 135(12): 1993-6.

[30] Doblhofer K, Nölte D, Ulstrup J. Polymer-film covered electrodes of stable electrochemical performance. Ber Bunsenges Phys Chem 1978; 82(4): 403-8.

[31] Ambegaokar V, Halperin BI, Langer JS. Hopping conductivity in disordered systems. Phys Rev 1971; B4: 2612-20.
[32] Leiva E, Meyer P, Schmickler W. Electron transfer through passive films: role of localized electronic states. Corros Sci 1989; 29(2): 225-36.

[33] Lu YC, Clayton CR. Evidence for a bipolar mechanism of passivity in Mo bearing stainless steels. J Electrochem Soc 1985; 132(10): 2517-8.

[34] Venugopal A, Macdonald DD, Varma R. Electrochemistry and corrosion of beryllium in buffered and unbuffered chloride solutions. J Electrochem Soc 2000; 147(10): 3673-9.

[35] Macdonald DD, Engelhardt GR. Proceedings of the 8th International Symposium on the Passivity of Metals and Semiconductors. Jasper, Alberta, Canada, May 9-14, 1999.

[36] Tun Z, Noel JJ, Shoesmith DW. Electrochemical modification of the passive oxide layer on a Ti film observed by in situ neutron reflectometry. J Electrochem Soc 1999; 146(3): 988-94.

[37] Macdonald DD, Ismail KM, Sikora E. Characterization of the passive state on Zinc. J Electrochem Soc 1998; 145(9): 3141-9.

[38] Ellerbrock DJ, Macdonald DD. Concerning passivity breakdown on solid and liquid gallium and titanium in halide solutions. Mater Sci Forum 1995; 185-188: 927-36.

[39] Milosev I, Metikos-Hukovic M, Drogowska M. Breakdown of passive film on copper in bicarbonate solutions containing sulfate ions. J Electrochem Soc 1992; 139(9): 2409-18

[40] Macdonald DD. The point defect model for the passive state. J Electrochem Soc 1992; 139(12): 3434-49.

[41] Zhong QD. Potential variation of a temporarily protective oil coating before its degradation. Corros Sci 2001; 43(2): 317-24.

[42] Zhong QD. Electrochemical technique for investigating temporarily protective oil coating. Prog Org Coat 1997; 30(4): 213-8.

[43] Zhong QD. Wire beam electrode: A new tool for investigating electrochemical inhomogeneity of oil coatings. Prog Org Coat 1997; 29(6): 279-85.

[44] Zhong QD. A novel electrochemical testing method and its use in the investigation of the self-repairing ability of temporarily protective oil coating. Corros Sci 2002; 44(6): 1247-56.

[45] Zhong QD, Zhang Z. Study of anti-contamination performance of temporarily protective oil coatings using wire beam electrode. Corros Sci 2002; 44(12): 2777-87.

[46] Zhong QD, Rohwerder M, Zhang Z, Zheng J. Semiconducting behavior of temporarily protective oil coating on the surface of AISI 304 Stainless Steel in 5\% Na2SO4 solution during its degradation. J Electrochem Soc 2004; 151(7): B446-B452.

[47] Wielant J, Goossens V, Hausbrand R, Terryn H. Electronic properties of thermally formed thin iron oxide films. Electrochim Acta 2007; 52(27): 7617-25.

[48] Goodlet G, Faty S, Cardoso S, et al. The electronic properties of sputtered chromium and iron oxide films. Corros Sci 2004; 46(6): 1479-99.

[49] Kulkarni SS, Lokhande CD. Structural, optical, electrical and dielectrical properties of electrosynthesized nanocrystalline iron oxide thin films. Mater Chem Phys 2003; 82(1): 151-6.

[50] Zhong QD, Xu NX, Zhou GD, Rohwerder M. Electronic-ionic conducting transition of temporarily protective oil coating in salt solution. Werkstoffe Korrosion 2003; 54(2): 97-105. 